DOI 10.15826/umpa.2019.05.042

\title{
ENTREPRENEURSHIP EDUCATION IN RUSSIA: INFLUENCE OF REGIONAL STAKEHOLDERS
}

\author{
A. A. Yashin ${ }^{a}$, D. Williams ${ }^{b}$, A. K. Klyuev ${ }^{a}$, A. P. Bagirova ${ }^{a}$ \\ ${ }^{a}$ Ural Federal University named after B. N. Yeltsin \\ 19 Mira str., Yekaterinburg, Russia,620002; a.k.kluev@urfu.ru \\ ${ }^{b}$ Enterprise Action Consulting \& Training Ltd
}

\begin{abstract}
Entrepreneurship education is one of the "youngest" segments in Russian higher education. a lack of history and established practices in the development of educational programmes for entrepreneurs negatively affects the quality of entrepreneurship education at universities; therefore, the role of internal and external stakeholders in the development and improvement of entrepreneurship curriculum is growing.

This article analyses the practices of Russian universities in the development of educational programmes for entrepreneurs. Key research foci include the structure of competencies specified in those programmes and their alignment with regional entrepreneurship development.

A number of research hypotheses were formulated, including those concerning the transformation of entrepreneurship curriculum under the pressure of stakeholders' demand for soft skills, heterogeneity of entrepreneurship curriculum as the result of differences between regional entrepreneurial ecosystems, and involvement of internal and external stakeholders in the creation of entrepreneurship curriculum.

The data presented in the article were obtained from open sources, such as the websites of universities implementing courses of entrepreneurship education.

The main results of the study include:

1) An integrated model of soft skills structure as a methodological platform for research in the sphere of entrepreneurship education.

2) Identification of regional differences in entrepreneurship curriculum.

3) Testing the hypothesis concerning the impact of entrepreneurial ecosystem factors on the state of entrepreneurship education.

4) Identify problems for future research with regard to interaction between all the actors and institutions of regional entrepreneurship ecosystems.

Keywords: entrepreneurship education, cognitive skills, social skills, action-oriented skills, stakeholder, entrepreneurship curriculum, syllabus, entrepreneurial ecosystems, regional development.

For citation: Yashin A. A., Williams D., Klyuev A. K., Bagirova A. P. Entrepreneurship education in Russia: Influence of Regional Stakeholders. University Management: Practice and Analysis. 2019; 23(5): 64-74. DOI: 10.15826/umpa.2019.05.042
\end{abstract}

\section{Introduction}

Russian entrepreneurship began its development relatively recently, in 1990s. Presently, this social group includes roughly 5.8 million people ${ }^{1}$ and accounts for $19.7 \%$ of the gross national income ${ }^{2}$.

Today, the educational needs of entrepreneurs are satisfied by various sectors of education, including universities. During the shaping of entrepreneurial ecosystems, such training was largely ensured by

${ }^{1}$ Edinyui reestr subektov malogo i srednego predprinimatelstva [Single register of small and medium-sized enterprises], available at: https://rmsp.nalog.ru/index.html (accessed 01.11.2019).

${ }^{2}$ Maloe i srednee predprinimatelstvo v Rossii 2017: Stat. sb. [Small and medium entrepreneurship in Russia]. Moscow, Rosstat, 2017. the system of non-formalized education providing short-term programmes and courses. However, the growth of innovative economy sectors increased the popularity of university entrepreneurship education. This resulted in the generation of new educational programmes, and their number has considerably increased over the past 15 years; however, the development of high-quality programmes in this field is significantly hampered by the following reasons:

- Limited number of university staff having entrepreneurship experience;

- Weak ties between universities and stakeholders from the entrepreneurial community;

-Reluctance of universities to be involved in the development of regional entrepreneurial ecosystems; 
-Outdated approaches to the development of entrepreneurship curriculum, which largely ignore the growing role of soft skills in contemporary society [1].

All of the aforementioned reasons led to entrepreneurs' widespread dissatisfaction with the quality of education, especially with insufficient attention to the development of soft skills [2]. At the same time, universities were reluctant to change their entrepreneurship programs. This discrepancy between entrepreneurs' requirements and existing university training programmes has stimulated research interest to the problem of bridging a gap.

Therefore, in this research, we aim to study the structure of competencies forming the basis of current entrepreneurship curriculum in Russia.

\section{Literature Review}

A number of studies conducted during the 20162018 period had analysed various programmes realized during entrepreneurship education in Russian universities in terms of a balance between hard skills and soft skills. a particular focus was to elucidate how this balance affects the overall quality of entrepreneurship education. Issues involved with the regional specifics of entrepreneurial programmes were also discussed.

To date, the structure of hard skills has been extensively studied by D. Autor, F. Levy and R. Murnane [1], as well as by one of the leading theoreticians in entrepreneurship education B. Johannisson [2]. However, the role and structure of soft competencies in higher education curricula have not been well defined. a new theoretical approach to the understanding of those competencies is required; that will help develop better curriculum for entrepreneurship training.

According to the work "Skills of an Effective Administrator" published in 1974 by American social and organizational psychologist Robert Katz [3], the three basic types of management skills include technical, conceptual and human or interpersonal skills. Technical skills involve skills that give the managers the ability and the knowledge to use a variety of techniques to achieve their objectives. Conceptual skills involve the skills managers present in terms of the knowledge and ability for abstract thinking and formulating ideas. The manager is able to see an entire concept, analyze and diagnose a problem, and find creative solutions. The human or the interpersonal (soft skills-authors) are the skills that present the managers' ability to interact, work or relate effectively with people. These skills enable the managers to make use of human potential in the company and motivate the employees for better results.
The very first studies devoted to the balance between hard and soft skills in the field of management and business argued that the latter only complement the former. According to D. Kirby [4], hard skills were supposed to be major abilities that any professional engineer, manager or businessperson should possess. However, an experimental study undertaken in 2008 [5] provided evidence that, although employers primarily appreciated well-developed hard skills, employees mentioned the lack of soft skills as impediment to be effective in their workplace. At the moment, this situation is rapidly changing. It is widely accepted today that soft skills are the key competencies for success in such fields as management and entrepreneurship. Hard skills are believed to complement soft skills in the shaping of an effective manager or entrepreneur.

From the middle of 1950 s onwards, the concept of soft skills has been under constant evolution. Present-day discussions are mainly focused on the issue of the versatility of soft skills. Some researches argue that practically any person, irrespective of their psychophysiological or personal qualities, can develop a basic set of soft skills [6]. However, the opposite point of view implies that psychophysiological and personal features play an essential role in the development and application of soft skills $[7,8]$. The latter approach is often used to justify entrepreneurial abilities as inborn personal qualities. Some researches, e. g. T. Kantorowitz [9], argued that the degree of soft skills performance can vary significantly throughout a person's lifeeither improve or degrade - due to accumulated experience, obtained education, etc. We believe that this is the most suitable approach for addressing challenges faced by universities in the creation and development of entrepreneurship curriculum. Hence, this theoretical prerequisite forms the methodological basis of our study.

There is no agreement among researchers concerning the structure of soft skills that a modern professional should possess. According to the results of a multi-country study, the most significant soft skills sought by European employers [10] include:

1. Capacity to "navigate the world of work", including such skills as goal-setting, learning ability, adaptability and flexibility, motivation, recognition of corporate values, respect for hierarchal levels, readiness to take responsibility, time management and digital skills.

2. Social skills, which include stress management, team working, leadership, conflict management, cross-cultural awareness and the ability to manage communication. 
3. Ability to achieve results, i.e. decision making, problem solving, creativity, focus on innovation, critical thinking.

In their "Recommendations on key competences for lifelong learning" [11], the European Parliament and the Council set forth the following most important soft skills:

1. Communication in the mother tongue.

2. Communication in foreign languages.

3. Mathematical competence and basic competences in science and technology.

4. Digital competence.

5. Learning to learn.

6. Social and civic competences.

7. Sense of initiative and entrepreneurship.

8. Cultural awareness and expression [11].

It is considered that core competences are those, which all individuals need to master for personal fulfilment and development, active citizenship, social inclusion and employment in a changing knowledge society [11]. It is notable that entrepreneurship is one of such key competences.

Another important research task is to specify which soft skills are particularly important for an entrepreneur. The Partnership for the 21st Century Learning, an organization under the aegis of UNICEF, suggests the following structure of soft skills underpinning successful entrepreneurship [12]:

1. Life and career skills - adaptability and flexibility, initiative, leadership, responsibility, self-direction, interaction, empathy, social skills, team work.

2. Learning and innovation skills - capability to see opportunities, creative and innovative thinking, creative resource using, critical thinking, communication, perspective thinking.

One can see that the categories of soft skills described above largely overlap, which has also been confirmed by numerous research studies [13, 14, 15]. Soft skills play an increasingly important role in entrepreneurship, being the key to creation and development of entrepreneurial networks and entire ecosystems. It should be noted that success in the entrepreneurial sphere is determined by the readiness to act, work in a high-risk environment, make prompt decisions and bear responsibility. M. Frese [15] described entrepreneurship as a conscious process of goal setting, planning to achieve a goal, monitoring and achieving success as a reward for a timely recognized opportunity. Focus on entrepreneurial actions also assumes initiative, self-regulation and self-management, self-efficacy and personal responsibility [15].

Following the assumption that the most important skills for entrepreneurs are those enabling them to act and make decisions under the conditions of high uncertainty and risk, we reviewed the studies considered to be important by most authors in the field of identification, typology and classification of competencies intrinsic to entrepreneurs. Thus, we analysed both classical works, e. g. by R. L. Katz [3] and contemporary research studies into the structure of entrepreneurial soft skills, e.g. by M. Frese [15], G. D. Markman [16], E. Chell and R. Athayde [17]. Fig. 1 generalizes the obtained data with a particular focus on entrepreneurial action. This structure was subsequently used as a guide for studying entrepreneurial skills included in entrepreneurship curriculum of Russian universities.

The suggested typology does not pretend to be comprehensive in terms of covering all entrepreneurial soft skills; rather, it sets out to outline those competencies that should be focused on by modern entrepreneurship curriculum.

\begin{tabular}{|l|l|l|}
\multicolumn{1}{|c}{ Cognitive skills } & Social skills & Action-oriented skills \\
\hline - Critical and analytical thinking; & - Oral and written & - Initiative; \\
\hline - Opportunity recognition and & communication; & - Goal-setting and \\
appraisal; & - Teamwork; & monitoring; \\
\hline - Problem solving; & - Leadership; & - Self-management; \\
\hline - Decision making; & - Collaboration; & - Self-efficacy \\
\hline - Creative and innovative thinking & - Network work & \\
\hline
\end{tabular}

Fig. 1. Structure of Entrepreneurial Soft Skills Developed by Entrepreneurship curriculum

$[3,15,16,17]$

In the following section, we will use the developed conceptual approach for creating a structural model of soft skills, which takes into account skills' levels of development and allows the balance between them to be estimated in the context of a given entrepreneurial ecosystem.

J. Moore, an American economist, was the first to use of the notion of an "ecosystem" in business and management to describe competitive processes. The ecosystem was understood as a complex network of suppliers, sales channels and consumers of goods and services. The distinguishing features of such networks included complexity, dynamic nature, openness, evolution, symbiosis, diversity, cooperation, competition and flexibility [18].

Using the institutional approach, C. Mason and R. Brown significantly expanded the ecosystem framework by proposing to consider not only entrepreneurs and their businesses, but also different institutions, as well as the processes of entrepreneurial activities (e.g., dynamics of appearing and disappearing companies, level of entrepreneurial aspirations) [19]. Actors form an entrepreneurial ecosystem directly or indirectly, thus determining its effectiveness. One of the well-known researchers of 
this issue $-D$. Isenberg - considered entrepreneurial ecosystems as a complex conglomeration of various interconnected institutional elements and links between them determining both the development of entrepreneurial ecosystems and the effectiveness of the entrepreneurship sector in economy [20]. Moreover, D. Isenberg outlined the necessity to use and transfer successful entrepreneurial experience in support of first-time entrepreneurs, along with the essential factors ensuring resilience of entrepreneurial ecosystems. Apart from the above-mentioned researchers, R. Adner, B. Mercan, D. Goktas and S. Durst [21, $22,23]$ also studied the issues of shaping and development of entrepreneurial ecosystems. It was established that the components of an ecosystem favourable for entrepreneurs include both statutory regulation of business environment, which promotes equal rights and opportunities for all the entities of an entrepreneurial society; effective systems and technologies at all levels providing equal educational opportunities both for entrepreneurs and their employees; availability of funds and financing; supporting culture ensuring an adequate evaluation of the significance of entrepreneurship [24].

The definition of the entrepreneurial ecosystem proposed by C. Mason and R. Brown [19] has found wide application. The entrepreneurial ecosystem is a set of interconnected entrepreneurial actors (potential and existing), entrepreneurial enterprises (companies, investors, business-angels, banks), institutions (universities, public services, and financial authorities) and entrepreneurial processes (number of forged businesses, number of high growth firms, number of serial entrepreneurs, level of entrepreneurial ambitions), which merge formally or informally, mediate and regulate the performance within the local entrepreneurial environment [19].

Research into entrepreneurial ecosystems in Russia began only about 15 years ago, on the basis of foreign publications in this field. Thus, N. M. Smirnova and E. A. Mironova suggested a classification of institutional factors determining the shaping and development of entrepreneurial ecosystems highly similar to that proposed by C. Mason and R. Brown [25]. The components of the entrepreneurial ecosystem were grouped as follows: favourable culture (acceptance of risk and errors, positive social status of an entrepreneur); social leaders and policy assistance; allocated funding (support of business-angels, venture capital, micro loans); appropriate human capital (qualified and non-qualified workforce, serial entrepreneurs, entrepreneurship training programmes); sales market (early followers, clients) and a wide range of institutional and infrastructure support (legal and accounting consulting, telecommunications and transport infrastructure, entrepreneurship promotion associations) [19].

It should be noted that Russian studies are mainly focused on studying either regional entrepreneurial ecosystems or specific aspects of business activities, such as youth entrepreneurship or innovative ventures.

The ecosystem approach is broadly used by researchers investigating entrepreneurship both in Russia and abroad. The interdisciplinary character of the entrepreneurial ecosystem concept predetermines application of diverse methodological approaches, including evolutionary, institutional, contextual and sociocultural ones. This diversity prevents from having a single view on the essence and structure of an "entrepreneurial ecosystem" [25].

In our research, we used the institutional approach to the analysis of entrepreneurial ecosystems. This approach allows an entrepreneurial ecosystem to be treated as a dynamic process of interaction between the actors, which affects the shaping and development of the ecosystem institutions, including entrepreneurship education.

The review of international and Russian research has shown that entrepreneurship education is a key factor in the successful development of entrepreneurial ecosystems. Subsequently, entrepreneurial ecosystems should also influence the state of entrepreneurship education through the following factors:

- The entrepreneurial ecosystem's degree of development. a highly-developed entrepreneurial sector in a region, which accounts for a considerable share of the gross regional product, will form a strong demand for a high-quality education system.

- Complexity of an entrepreneurial ecosystem. The complex entrepreneurial ecosystems are characterized by the vast variety of businesses from different sectors of economy; thus demanding much more variety of majors from its universities.

Entrepreneurial systems characterized by a high level of diversity, i. e. consisting of numerous enterprises working in various economic directions, will require a wide spectrum of unique specialists. Alternatively, entrepreneurial monosystems (e.g. when the majority of companies are engaged in trade and service or in just one type of manufacturing) will require specialists with standard (routine) qualifications.

- Specificity of an entrepreneurial ecosystem. The level of production diversification in a region determines the specificity of its entrepreneurial ecosystem. The predominance of innovative trade and service companies or social entrepreneurship will create a demand for specialists with highly specific skills. 
For example, the development of innovative entrepreneurial projects in a region will require entrepreneurs to have knowledge in venture capital management and, therefore, specific cognitive skills.

- A degree of integration with the education system in a region. a high level of integration between the entrepreneurial ecosystem and the education system indicates that universities maintain a permanent contact with the entrepreneurial environment, monitoring its demand for specialists. On the other hand, the entrepreneurial ecosystem sets its own demands for specialists to the educational system. Ideally, entrepreneurship educational programmes are the result of collective actions of all stakeholders. In this process, three main groups of stakeholders can be defined: the university implementing entrepreneurship curriculum represented both the developers of such programmes and the academic staff; the regional entrepreneurial ecosystem (entrepreneurial community); and the consumers of educational services, i. e. students.

Each of the abovementioned stakeholder groups has an effect of the quality of entrepreneurship curriculum, thus determining the ultimate result, i. e. the shaping of an entrepreneur with the required set of skills. The developers and the academic staff are responsible for the structure and content of educational programmes. In this respect, two important aspects should be mentioned. First, university programmes in Russia are developed based on the requirements of the RF State Educational Standards determining the set of developed competencies; however, there is no RF State Educational Standard regarding entrepreneurship education. Entrepreneurship programmes are typically developed on the basis of other training programmes (e.g. "Economics" or "Management"), which in most cases are missing competencies required by entrepreneurs. Second, entrepreneurship programmes are developed as a rule by academic staff lacking either practical experience or academic training in the field of entrepreneurship. As a result, the patterns traditional for such subjects as economics, management or business are automatically transferred to entrepreneurial programmes. These reasons explain why there are very few high-quality programmes in the field of entrepreneurship at Russian universities and why the majority of Russian entrepreneurship curricula are imitative by nature.

The task of entrepreneurial communities consists of forming and voicing a demand for particular entrepreneurial skills (both hard and soft). The system of higher education should take into account the requirements of the entrepreneurial ecosystem and strive to meet them by developing appropriate entrepreneurship curriculum.
According to the data by the "Global University Entrepreneurial Spirit Students' Survey" [26], 74\% of Russian students expect to be employed after graduation, compared to only $9 \%$ who plan to start their own business. On the one hand, this numbers are consistent with the international ones. On the other hand, it can be assumed that no more than $10 \%$ of students are capable of clearly formulating the requirements concerning specific entrepreneurial skills they would need in the future.

Hence, out of the three main stakeholder groups contributing to entrepreneurship education, one is external to the university (entrepreneurial ecosystems) and two (academic staff and students) - are internal. It can also be assumed that, in reality, universities implementing educational programmes in the field of entrepreneurship should respond to the needs of all three main stakeholder groups. Therefore, the structure, content and quality of entrepreneurship programmes in every particular case should depend on the balance of such requirements.

As a rule, stakeholders' requirements are fully taken into account in universities preparing to get (or having already received) international accreditation. Essential criteria for international accreditation in the field of higher education is to demonstrate that a university addresses successfully the needs of labour market and students, and that the academic staff is actively engaged in modernization of educational environment and curricula.

Universities in different countries have accumulated a lot of experience in engaging stakeholders in designing entrepreneurial programmes. However, as it was mentioned above, Russian universities presently demonstrate weak dynamics in the development of this type of programmes. This, in our opinion, creates a gap between the demand for contemporary entrepreneurship curriculum, in which the soft and hard skills are well balanced, and the supply coming from regional universities. In order to address this issue, we set the following objectives:

1. Identify a structure of soft skills that should be developed in entrepreneurship education.

2. Identify regional differences in entrepreneurial programmes regarding soft skills.

3 . Identify the influence of entrepreneurial ecosystem factors on the balance of soft skills in entrepreneurial programmes.

4. Define measures of bridging the gap between demand and supply in entrepreneurship education.

The following research hypotheses were formulated:

1. The structure of soft skills in entrepreneurship education should have a dynamic pattern and undergo 
transformation in the context of stakeholders' changing demand. The structure of soft skills is assumed to be heterogeneous. The proposed distinction between cognitive skills, social skills and action-oriented skills has a dynamic character and reflects transformations in the field of entrepreneurial activities. Since the problem of soft skills in entrepreneurial programmes was not discussed earlier, an analysis should be carried out to investigate the current status and to identify factors of external environment affecting the existing structure of soft skills.

2. Regional ecosystems form a demand for skills in the context of their regional development specifics. It is hypothesized that regions differ in terms of demand for soft skills as a result of historical division of labour, specialization, the structure of economy, existing norms, customs and traditions. In this work, we aim to identify regional differences in the structure of entrepreneurial skills and to provide assumptions regarding their origin.

3. Regional entrepreneurial ecosystems affect the structure and content of entrepreneurship education. It is assumed that some factors of ecosystems can be treated as more important or neutral in term of shaping a demand for soft skills. In this work, we set out to identify the most essential elements of entrepreneurial ecosystems having an effect on the structure of competencies by analysing their connection with the key indicators specific to these ecosystems.

\section{Data and Methods}

The methodological framework for our study was the theory of action as the key concept in the understanding of entrepreneurship and entrepreneurs as active actors of the market environment. a review of research linked to this concept allowed us to identify 3 groups of soft competencies, i. e. cognitive skills, social skills and action-oriented skills. The subject matter of our study was the development of these skills during the implementation of the entrepreneurship curriculum. The development of soft skills was considered to be the result of cooperation between universities and regional entrepreneurial ecosystems. From the standpoint of institutional theory, the entrepreneurial ecosystem is a space for interaction between various actors and the links between them.

Empirical data were extracted from open sources, such as the websites of Russian universities implementing entrepreneurship curriculum. According to the disclosure policy, the website of any higher education institution in Russia must present exhaustive information about educational programmes it implements, including their detailed curriculum and syllabi for all subjects, as well as a detailed description of developed competencies. The total amount of analysed data included:

- 44 curricula of entrepreneurial programmes implemented by universities in various regions (6 Federal districts);

$-2,359$ syllabi of disciplines and the same number of the sets of competencies.

Table 1 shows the distribution of the analysed programmes across RF Federal districts.

Table 1

\section{Number of programmes analysed in different Russian regions}

\begin{tabular}{|l|c|}
\hline \multicolumn{1}{|c|}{ Region } & Total number of programmes \\
\hline Central Federal District & 9 \\
\hline Volga Federal District & 13 \\
Southern Federal District & 3 \\
Ural Federal District & 6 \\
Siberian Federal District & 9 \\
Far Eastern Federal District & 4 \\
Total & 44 \\
\hline
\end{tabular}

We analysed the sets of competencies (skills) included in all the researched programmes. Every competency was referred to one of the following groups: cognitive, social and action-oriented ones.

Along with the analysis of the ratio between various competencies in the programmes, we also studied their regional differences. The next step was a correlation analysis between the entrepreneurial soft skills declared in the programmes and the specifics of entrepreneurial ecosystems in the regions.

An analysis of regional entrepreneurial ecosystems was carried out using the official statistics of the Federal State Statistic Service describing the innovation sector in Russian regions ${ }^{3}$. Although the indicators of the innovation sector characterize only one aspect of regional entrepreneurial ecosystem development, they have the advantage of reliability and availability. Indeed, these data are collected based on the annual Federal statistical monitoring procedure No.4-Innovation "Data about innovative activities of organizations".

For our analysis, we used the following indicators of the innovation sector in RF Federal Districts:

1. Volume of innovative products and services (1 indicator);

${ }^{3}$ Data about the innovation activities of the organization https:// www.gks.ru/free_doc/new_site/business/nauka/4-innov.htm (accessed 01.11.2019). 
2. Share of innovative products and services in the overall volume of goods, works and services (2 indicators);

3. Expenditures on technological innovations: the total amount and per every innovation (11 indicators);

4. Use of intellectual property objects per their types (6 indicators).

Overall, 20 statistical indicators were used to assess the state of regional ecosystems.

The collected data were analysed using the following statistical methods:

1) Methods of descriptive statistics (calculation of the averages, median values, shares, minimum and maximum values) for the analysis of entrepreneurship curriculum;

2) Kendall's and Spearman's rank correlation coefficients for the analysis of correlations between the indicators of entrepreneurship educational programmes and the state of regional innovation sectors. The choice of non-parametric instruments was determined by a small size of the statistical population and the absence of normalization in the distribution of initial data.

The main focus on the indicators of innovation is explained by the self-imposed limitation: to assess the performance of Russian universities based on innovative entrepreneurship as the most significant segment of the economy.

\section{Results and Discussion}

The obtained data allowed to evaluate the aboveformulated hypotheses.

The hypothesis about the complex and dynamic structure of soft skills developed by entrepreneurship education was generally confirmed. The structure of the researched curricula is the following: the majority of the curricula feature the disciplines which are developing cognitive skills (50\%-96.8\% of the total number of disciplines). Disciplines developing social skills are included in the curriculum less frequently $(20 \%-60 \%$ of the total number of disciplines). The least common are the disciplines focused on the development of action-oriented skills; only $7 \%-20 \%$ of the total number of disciplines. Since our analysis is the first of its kind, we can only make preliminary conclusions on the variability of soft competencies in the entrepreneurial programmes of Russian regional universities. Future research should identify factors of internal and external environment determining the balance of soft skills. At the moment, the identified orientation towards the development of cognitive skills cannot be considered problematic; however, the questions of how this balance is formed, due to which factors, how it correlates with the demand for competencies from the business community-all these issues require a detailed analysis. Therefore, it can be said that our first hypothesis, rather than providing exhaustive answers has formed a basis for further investigation. The proposed methodological approach to the analysis of soft skills has shown its research potential for the future studies.

The second hypothesis claimed that regional entrepreneurial ecosystems form their own specific demand for competencies, which is underscored by the region's specialization and institutions. Our regions' analysis showed that there are certain quantitative differences in shares of disciplines with a particular type of skills, in spite of the fact that the structure of soft competencies in educational programmes is sufficiently similar among the analysed regions,. Since the number of groups of programmes in the context of regions is rather small, we used the median value of these shares. Table 2 presents minimum and maximum shares of disciplines with different types of skills in Russian regions.

One can see that the share of social skills and action-oriented skills in the researched programmes differs significantly. With respect to the social skills share, universities in the Ural Federal District stand out. Fig. 1 shows a diagram with the median share of these disciplines in curricula.

Minimum and maximum regional median shares of disciplines in curricula by groups of skills

\begin{tabular}{|c|c|c|c|}
\hline \multirow{2}{*}{ Skill Group } & \multicolumn{2}{|c|}{$\begin{array}{c}\text { Median Share of Disciplines in Curricula with a Group of Skills for } \\
\text { a Region, }\end{array}$} & \multirow{2}{*}{ Maximum to Minimum Ratio } \\
\cline { 2 - 3 } & Minimum & Maximum & 1.10 \\
\hline Cognitive Skills & $\begin{array}{c}78.7 \text { (Ural Federal District) } \\
\text { Social Skills }\end{array}$ & $\begin{array}{c}26.8 \text { (The Southern Federal } \\
\text { District) }\end{array}$ & 56.9 (Volga Federal District) \\
Action-Oriented Skills & $\begin{array}{c}11.0 \text { (The Southern Federal } \\
\text { District) }\end{array}$ & $\begin{array}{c}26.3 \text { (The Central Federal } \\
\text { District) }\end{array}$ & 2.12 \\
\hline
\end{tabular}




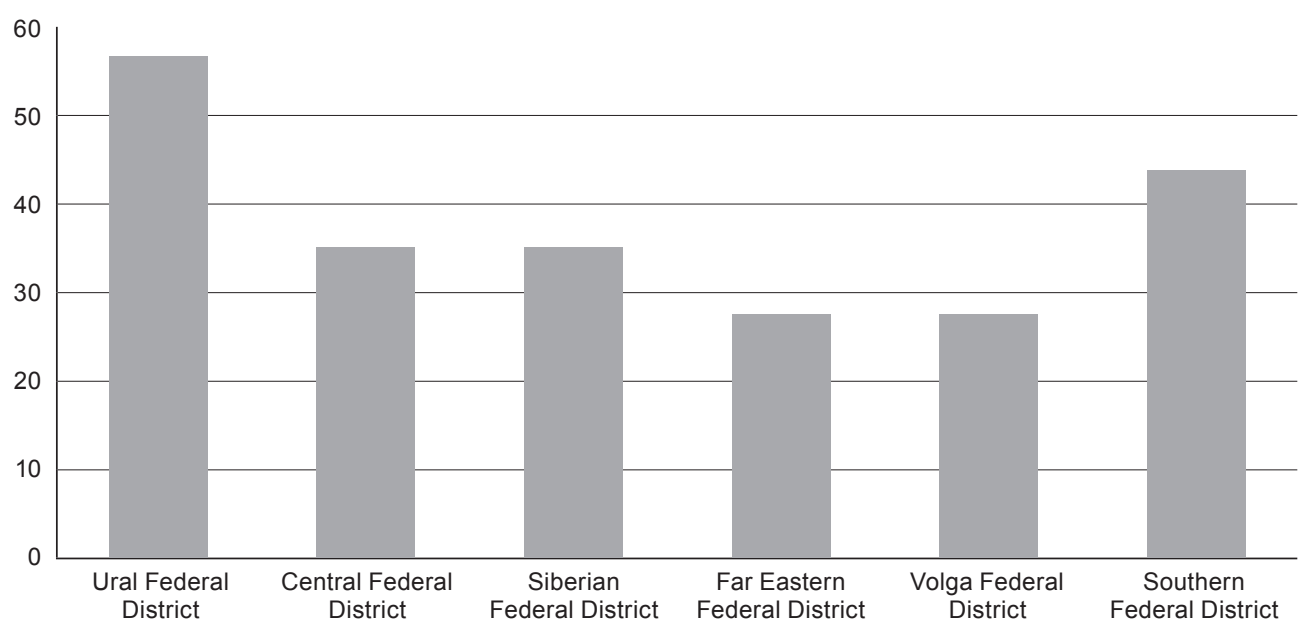

Fig. 2. Median share of disciplines focused on social skills development, by Russian regions

Regarding the disciplines developing action-oriented skills, two groups of regions were distinguished, i. e. those with the highest and the lowest share of such disciplines in entrepreneurship curriculum.

The analysis found statistically significant differences between the regions in their approaches to the shaping of soft competencies during implementation of entrepreneurship curriculum. In general, this confirms our hypothesis about regional specificity. The collected data show that these differences are not accidental and can hardly be explained by the subjectivity of programme developers. The discovered differences are most likely to reflect the regions' sociocultural specifics. The results have raised the following questions:

- How does the regional specifics of human capital in a particular region impact the demand for training entrepreneurs?

- What mechanisms and interactions between the entrepreneurial ecosystem actors ensure the identification of the demand for entrepreneurship education and its transfer to universities?

- How will be the soft skills in entrepreneurial programmes transformed in the process of the entrepreneurial ecosystem development?

- What factors and specific features of a region's entrepreneurial environment and culture have major influence on the demand for soft competencies?

All these questions will be explored in our future research. Such work requires significant efforts involving searching, processing and analysing information about the patterns of the development of entrepreneurial ecosystems; factors and specific features of entrepreneurial ecosystems, and particular aspects of the development of human capital in Russian regions. In addition, the interaction between the entrepreneurial environment and universities during the formation and transfer of demand for effective entrepreneurship curriculum remains to be further researched.

Our analysis showed almost no correlation (in $95 \%$ of cases) between the set of skills in the entrepreneurship curriculum and innovation sector status in Russian regions. However, a number of statistically significant correlations were identified. Thus, the share of disciplines featuring Cognitive Skills in the regions has a positive correlation with the expenditures on technological innovations related to de$\operatorname{sign}\left(r_{s}=0.867\right)$, meaning that the Federal districts, which offer more cognitive skills' disciplines, spend more resources on design technological innovations. However, no significant correlation was revealed concerning expenditures on other types of technological innovations.

Table 3

\section{Groups of regions with different shares of disciplines developing action-oriented skills in curricula}

\begin{tabular}{|l|c|l|c|}
\hline \multicolumn{1}{|c|}{ Group 1 } & $\begin{array}{c}\text { Range of the median share of dis- } \\
\text { ciplines focused on the develop- } \\
\text { ment of action-oriented skills }\end{array}$ & \multicolumn{1}{|c|}{ Group 2 } & $\begin{array}{c}\text { Range of the median share of dis- } \\
\text { ciplines focused on the develop- } \\
\text { ment of action-oriented skills }\end{array}$ \\
\hline $\begin{array}{l}\text { Central Federal District } \\
\text { Ural Federal District }\end{array}$ & $25.0-26.3$ & $\begin{array}{l}\text { Volga Federal District } \\
\text { Southern Federal District }\end{array}$ & $11.0-17.9$ \\
Far Eastern Federal District & Siberian Federal District & \\
\hline
\end{tabular}


Interestingly, a negative correlation was observed between the share of action-oriented skills in a discipline and a relative share of innovative products and services in the total volume of products shipped and services performed $\left(r_{s}=-0.943\right)$, as well as with a relative share of innovative products and services in the total volume of industrial production $\left(r_{s}=-0.886\right)$. The more action-oriented skills are taught in university curricula, the lower the innovative component share is in the total volume of products and services. However, no such correlations were observed concerning other types of skills. Another negative correlation was found between the share of only social skills' disciplines within entrepreneurship curriculum and the expenditures on technological innovations $\left(r_{s}=-0.812\right)$ in a region. The share of disciplines with action-oriented skills demonstrates a positive correlation with the use of intellectual property objects (intellectual micro-scheme topologies) in regions $\left(r_{s}=0.941\right)$.

It can concluded that our hypothesis about the correlation between the development of soft skills during entrepreneurship education and the characteristic features of the entrepreneurial ecosystem in a region has been partially confirmed. More reliable results can be obtained by analysing correlations between the soft skills developed during entrepreneurship training and the level of development of key institutions and actors in an entrepreneurial ecosystem, rather than by analysing statistical indicators reflecting their activity. Therefore, improved research instruments are needed to establish the relationship between the elements and factors of entrepreneurial ecosystems and the structure of required entrepreneurial skills.

In addition, the syllabi of entrepreneurship curriculum were analysed based on the set of competencies specified by RF State Educational Standards and each skill was referred to cognitive, social or actionoriented. However, quite frequently, one discipline can address a number of skills belonging to different groups.

Another important fact is that practically all the studied entrepreneurship curricula, regardless of the training field for which they were created, comprise a very similar set of subjects aimed at developing professional competencies. These are mainly subjects related to either economics ("Fundamentals of Economics", "Economics of Organization", "Economic Theory", etc.) or management ("Strategic Management", "Project Management", "Corporate Management", etc.). Interestingly, the lists of competencies specified by RF Federal State Educational Standards does not include competencies directly related to the development of entrepreneurial skills and expertise. It can, therefore, be concluded that the entrepreneurship curricula replicate the curricula of other fields without focusing on the development of entrepreneurial competencies.

A significant feature of all higher education programmes in Russia, including those for entrepreneurs, is their strict compliance with RF Federal State Educational Standards. These Standards regulate both the structure of educational programmes and the list of competencies that students should develop. Although a university is free to complement the basic programmes with subjects aimed at forming some specific competencies, the list of competencies and the content of competencies cannot be changed.

However, in order to develop a well-balanced and effective model of soft skills formed during entrepreneurship education, universities should continue seeking new forms of interaction between all the involved stakeholders and investigate the sociocultural features of entrepreneurial ecosystems.

\section{Conclusion}

The analysis of practices aimed at developing entrepreneurship curriculum at Russian regional universities allowed us to identify a number of issues, which should be addressed in order to improve the current state of entrepreneurial ecosystems in Russia.

First, the development of entrepreneurship curriculum in Russian higher education institution is characterized by a very slow dynamics, which does not correspond to either the global trends in the field or the growing share of the entrepreneurial sector in economy.

Second, the transition of Russian universities to the competency-based model of training, which began about a decade ago, is not supported by comprehensive studies of the structure of competencies and their transformation mechanisms. In addition, there is a lack of approaches to designing such competency-based models that would take into account stakeholders' interests, particular aspects of the entrepreneurial environment and regional sociocultural factors.

Third, the analysis of the structure of soft competencies, which are being developed by the current entrepreneurship curriculum, has shown its dynamic structure subjected to the influence of a region's entrepreneurial ecosystem. Since no similar studies have been conducted before, we aimed to verify the most general hypotheses concerning the internal links in the structure of soft skills and the as effects of the regional context and the entrepreneurial ecosystem. The obtained results allowed us to formulate a number of research questions for future analysis. 
Fourth, the revealed correlations between the content of entrepreneurship curriculum, regional factors and entrepreneurial ecosystem indicators raise the question of managerial decisions that could ensure the adequacy of university educational programmes to the requirements of entrepreneurial communities.

\section{References}

1. Autor D., Levy F., Murnane R. The skill content of recent technological change: an empirical exploration. Harvard College and the Massachusetts Institute of Technology: The quarterly journal of economics, November 2003, pp. 1279-1333. (In Eng.).

2. Johannisson B. University training for entrepreneurship. Swedish approaches Entrepreneurship \& Regional Development: An International Journal, 1991, no. 3, pp. 67-82. (In Eng.).

3. Katz Robert L. 1955. 'Skills of an Effective Administrator'. Harvard Business Review, 1995, no. 33 (1), pp. 33-42. (In Eng.).

4. Kirby David. 'Changing the Entrepreneurship Education Paradigm'. In Handbook of Research in Entrepreneurship Education: a General Perspective, edited by Alain Fayolle. Edward Elgar Publishing, 2007, pp. 21-33. (In Eng.).

5. Andrews Jane, and Helen Higson. "Graduate Employability, "Soft Skills" Versus "Hard" Business Knowledge: a European Study'. Higher Education in Europe, 2008, no. 33 (4), pp. 411-422. (In Eng.).

6. Matteson Miriam L., Lorien Anderson, and Cynthia Boyden. "Soft Skills": a Phrase in Search of Meaning'. Portal: Libraries and the Academy, 2016, no. 16 (1), pp. 71-88. (In Eng.).

7. Robles, Marcel M. 2012. 'Executive Perceptions of the Top 10 Soft Skills Needed in Today's Workplace'. Business Communication Quarterly, 2012, no. 75 (4), pp. 453-465. (In Eng.).

8. Ward Anne.'Enterprise Skills and Enterprise Learning'. Foresight, 2004, no. 6 (2), pp. 104-109. (In Eng.).

9. Kantrowitz, Tracy Michelle. Development and Construct Validation of a Measure of Soft Skills Performance. Georgia Tech, 2005, available at: https://smartech.gatech.edu/ handle/1853/6861. (accessed 28.10.2019). (In Eng.).

10. Cross-Country Survey on Soft Skills Mostly Required by Companies to Medium/High Skilled Migrants. Methodological approach for a common framework of Soft Skills at work. Ceipiemonte Scpa. Italy. 2015. This publication is supported by Programme Erasmus+. (In Eng.).

11. Union Europe Parliament recommendations about the main competentions of education in a lifetime] (2006/962/ EC). published: L 394/18 EN Official Journal of the European Union 30.12.2006, available at: http://www.eur-lex.europa.eu/ LexUriServ/site/en/oj/2006/1_394/1_39420061230en00100018. pdf (accessed 28.10.2019). (In Eng.).

12. Partnership for 21st Century Learning. 'Framework for 21st Century Learning'. Partnership for 21st Century Learning, 2019. (In Eng.).

13. Holmberg-Wright Kristin, and Tracy Hribar. 'Soft Skills - The Missing Piece for Entrepreneurs to Grow a Business'. American Journal of Management; West Palm Beach, 2016, no. 16 (1), pp. 11-18. (In Eng.).

14. Jackson Denise. Testing a Model of Undergraduate Competence in Employability Skills and Its Implications for Stakeholders. Journal of Education and Work, 2014, no. 27 (2), pp. 220-242. (In Eng.).

15. Frese Michael. 'The Psychological Actions and Entrepreneurial Success: An Action Theory Approach' In The Psychology of Entrepreneurship, edited by J. Robert Baum, Michael Frese, and Robert A. Baron, The Original Frontiers Series. Psychology Press, 2007, pp. 151-188. (In Eng.).

16. Markman Gideon D. Entrepreneurs' Competencies. In The Psychology of Entrepreneurship, edited by J. Robert Baum, Michael Frese, and Robert A. Baron. The Original Frontiers Series. Psychology Press, 2007, pp. 67-92. (In Eng.).

17. Chell Elizabeth, and Rosemary Athayde. 'Planning for Uncertainty: Soft Skills, Hard Skills and Innovation'. Reflective Practice, 2011, no. 12 (5), pp. 615-628. (In Eng.).

18. Moore J. F. "Business ecosystems and the view from the firm" (PDF). The Antitrust Bulletin, 2006, vol. 51(1), pp. 31-75. (In Eng.).

19. Brown R., Mason C. Raising the batting average: Re-orientating regional industrial policy to generate more high growth firms. Local Economy, 2012, vol. 27, no. 1, pp. 33-49. (In Eng.).

20. Isenberg D. Introducing the Entrepreneurship Ecosystem: Four Defining Characteristics, available at: http:// www.forbes.com/sites/danisenberg/2011/05/25/introducingthe-entrepreneurship-ecosystem-four-definingcharacteristics (accessed 28.10.2019). (In Eng.).

21. Adner R. Match Your Innovation Strategy to Your Innovation Ecosystem. Harvard Business Review, 2006, vol. 84, no. 4, pp. 98-107.

22. Durst S., Poutanen P. Success factors of innovation ecosystems: Initial insights from a literature review. CO-CREATE 2013: The Boundary-Crossing Conference on Co-Design in Innovation, Aalto University, 2013, pp. 27-38. (In Eng.).

23. Mercan B., Goktas D. Components of Innovation Ecosystems: a Cross-Country Study. International Research Journal of Finance and Economics, 2011, no. 76. (In Eng.).

24. Doroshenko S. V., Shelomentsev A. G. Predprinimatel 'skaya ecosistema v sovremennyukh socioekonomicheskikh issledovaniyakh [Entrepreneurial ecosystem in modern socio and economic researches]. Journal of economic theory, 2017, No. 4, pp. 212-221. (In Russ.).

25. Mironova E. A., Smirnova N. M. Sotsial'noe predprinimatel'stvo: faktory, vliyayushchie na razvitie [Social entrepreneurship: factors influencing to the development], Sotsial'no-ekonomicheskie preobrazovaniya i problemy [Socio-economic transformations and challenges], Nizhnii Novgorod, 2015, vol. 5. pp. 63-80. (In Russ.).

26. Shirokova G. V., Bogatyreva K. A., Belyaeva T. V., Laskovaya A. K., Karpinskaya E. O. Natsional'nyi otchet "Global'noe issledovanie predprinimatel'skogo dukha studentov. Rossiya 2018" [National report 'Global research of students' entrepreneurial mind']. Higher School of Management, Saint Petersburg, 2019, 53 p. (In Russ.). 


\section{Information about the authors:}

Aleksandr A. Iashin - PhD (Economics), Associate Professor of the Chair of Regional Economics, Innovative Entrepreneurship and Security, Ural Federal University; +7 (343) 371-10-03; a. a.yashin@urfu.ru

Dina Williams - PhD in Science, Technology and Innovation Management, Managing Director, Enterprise Action Consulting \& Training Ltd; +44-1423-865398; d.williams@enterpriseaction.co.uk

Alexey K. Klyuev - PhD (Philosophy), Associate Professor, Head of UNESCO Chair in University Management and Planning, Ural Federal University; +7 (343) 371-10-03; a.k.kluev@urfu.ru.

Anna P. Bagirova - Dr. hab. (Economics), PhD (Sociology), Professor, Professor of the Chair of Sociology and Technologies of Public Administration, Ural Federal University; +7 (343) 371-10-03; a.p.bagirova@urfu.ru.

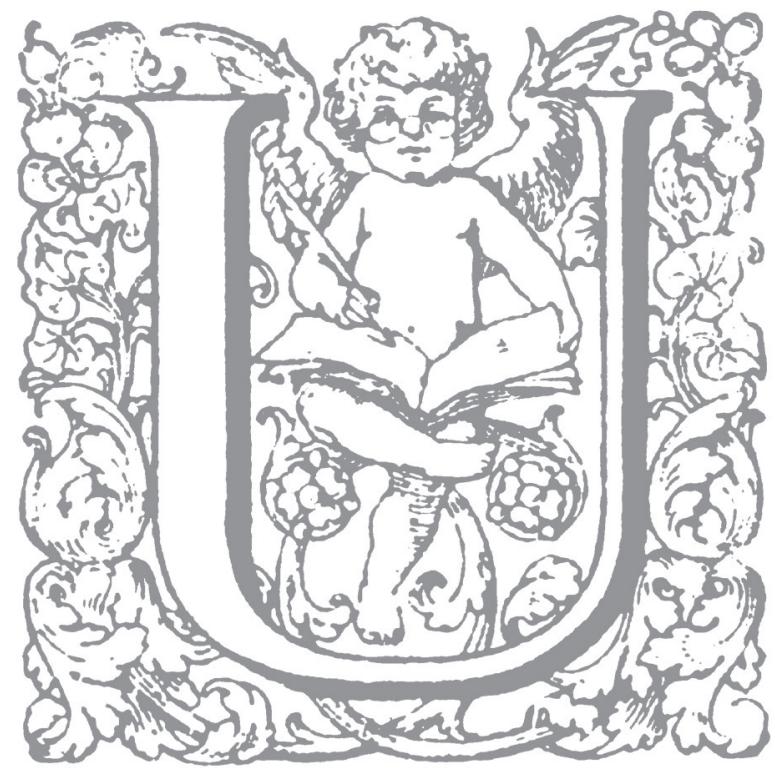

